\title{
Approximate noise maps as instrument for evaluation of the city environment quality
}

https://doi.org/10.1515/noise-2021-0021

Received Dec 31, 2020; accepted Jul 07, 2021

\begin{abstract}
The paper discusses noise mapping from the prospective of general evaluation of the state of the city environment. Suggested is a noise evaluation procedure based on a two-step spatial discretization - coarse and fine grids. The coarse grid is used for evaluation of average noise levels (background noise). For this, rather simple method is proposed, where average noise levels are estimated directly for the whole coarse grid cells instead of averaging the noise levels computed point-wise. The fine grid is used for finding the obstacle density to apply in calculations over the coarse grid. It may be used also for additional noise levels detailing in the close vicinity of noise sources where noise propagation is strongly affected by surrounding structures. The detailed results allow correction of the averages over the coarse grid. In comparison with other approaches, the suggested procedure takes little computing time to execute for the entire city. Test example shows reasonable agreement with results computed using the 'Ecolog-Noise' software package that has gained popularity in Russian Federation since its introduction in 2008. Another example describes the application of the proposed method for a moderate size densely built city.
\end{abstract}

Keywords: noise mapping, average noise level, mesh points

\section{Introduction}

Urban noise is an inherent part of the environment in big cities. It is one of the negative consequences of the development of the city infrastructure. There are numerous studies confirming the negative impact of noise on the quality of the life of the population $[1,2,3]$. Noise even affects chil-

\footnotetext{
`Corresponding Author: Alexander Ziv: Electrotechnical University "LETI", Department of Mathematics, 197376 Saint Petersburg, Russian Federation, E-mail: sasha-ziv@mail.ru

Elena Solov'eva: Saint Petersburg State University of Architecture and Civil Engineering, Department of History and Philosophy, 190005 Saint Petersburg, Russian Federation
}

dren's mental development and school performance [4]. Prioritization and choice of noise protective measures on the city scale require information about spatial and temporal distribution of noise levels. Noise maps - current and projections - can be very useful, for instance, to city planners for designing and approving new construction or for improving the existing living spaces.

Noise mapping is considered in numerous works, various computing systems and models are involved, often in combination with measurements in order to correct errors that are inevitable in mathematical modeling of noise propagation processes. Models differ in details, but most are based on the concepts of geometric acoustics taking into account the main features of noise propagation including attenuation due to shielding, reflection, weather conditions, etc.

Among the most well-known software packages are SoundPlan (http://www.soundplan.eu/english/soun dplan-acoustics/), CadnaA (www.datakustik.com), NORD2000 (http://eng.mst.dk/topics/noise/trafficnoise/nord2000-nordic-noise-prediction-method), HARMONOISE [5], FHWA TNM (https://rosap.ntl.bts .gov/view/dot/48763) developed in the EU and the USA, ARM Acoustics (http://www.noiseview.ru/conten t/3d.html) and Ecolog-Noise (http://integral.ru/shop/c argo/141.html) developed in Russian Federation. The latest commercial software follow guidelines published in Common Noise Assessment Methods in Europe (CNOSSOS-EU) [6], which partly is the development of the former International Standard ISO 9613-2: 1996 (ISO) (https://www.iso.org/obp/ui/\#iso:std:iso:9613:-2:ed1:v1:en).

Development of noise mapping systems in the last decade is driven by Environmental Noise Directive EU 2015/996 [7]. For noise mapping purpose, advanced noise propagation models get integrated with GIS systems. This allows automatic presentation of noise levels in static and dynamic mode.

Noise mapping projects for Madrid [8] and Paris [9] boosted progress in development of noise mapping strategies. The success partly is due to reduction in the cost of the instrumental part but probably more because of im- 
provement and optimization of computational algorithms. For instance, in DYNAMAP project for Milan $[10,11]$ static noise maps were prepared in advance for a set of typical situations and a predefined set of road stretches, something like the matrix of maps. For any particular moment, the appropriate maps then could be chosen, thus reducing computing time significantly. Another time saving feature in DYNAMAP was rather simple procedure for assimilation of measurement data. With this approach, moving from static to dynamic maps did not take a lot of time. Unfortunately, it is not indicated in [10] how long it took to map the Milan area on the $10 \mathrm{~m}$ grid and what details of the city environment were accounted for. In another work [12], the spatial-temporal correction was used for interpolation of modelling results and correction of some model parameters. This approach provided a compromise between model performance and its computational cost.

The scale and configuration of the scene put forward requirements for the set of input data and discretization of the sources and computational domain. When computational cost becomes critical, we need to switch off some features of the software and/or simplify scene parameters. The scale and extent of discretization depend also on the aim of calculations. It is rather evident that the contribution of road noise is the highest in the close vicinity of the road. If we consider the compliance with the standards for allowable noise levels and permissible exposure at a particular place, one can limit the scale of precise discretization by road proximity. Here, the discretization of built-up area is a challenge, but this area is quite limited.

Since city road transport is main cause of noise pollution, its treatment in noise propagation models is one of the crucial points. The main problem is the segmentation of the road. The receptor-house-road projection approach requires recalculation of road partition for each receptor. For keeping accuracy without projections, the finer road partitioning is needed. A slightly different approach is a fixed partitioning of sources, primarily roads, with its linking to a GIS grid, on the basis of which or with the help of which noise mapping is carried out [13,14, 15].

City scale computations need simplifications and appropriate choice of computational domains and sets of grid points. It seems reasonable to divide the space, on which the noise assessment is carried out, into separate areas: zones located near the noise sources and the rest ones, where city geometry can be taken into account very approximately $[16,17,18]$. A number of works devoted to the assessment of the background noise in the city analyze possible errors associated with insufficient consideration of local features [19, 20]. As to the grid choice, it is shown in [21] that both source oriented irregular grid and/or derivative free optimization helps significantly in case of air pollution mapping. Similar considerations can be applied to the noise mapping, at least in principle.

Nowadays, in large cities in calculations of air pollution for the entire city are regularly carried out using the emissions inventory from all urban sources. The results are used for evaluation of the state of the city environment, planning of mitigation of air pollution, etc. The corresponding air pollution mapping is based on the concentration data obtained for usually uniform grid. The step size varies depending on the city size and the number of air pollution sources. As a rule, in big cities it is equal to $500 \mathrm{~m}$. To expand the characteristics of the urban environment by information on noise pollution, it may be useful to supplement the calculations of air pollution with calculations of average noise levels, linking the results to the same computational grid.

To evaluate whether noise averaged on the grid of this size (about $500 \mathrm{~m}$ ) can be a meaningful noise characteristic, we turned to studies in the field of environmental psychology. After all, some researches report complex and ambiguous relationship between objective characteristics of the environment and the subjective assessments of these characteristics by residents [22]. To determine how city residents perceive such environmental characteristics as noise and dust, we conducted a study among the students attending the University of Architecture and Civil Engineering (Saint Petersburg, Russia).

In our study, we utilized the method of mental maps and a questionnaire. Mental maps are visual geo-images that reflect individual ideas about a city or a part of it [23]. We asked the respondents to draw a map of the area that they perceived as their domain, that is where their outdoor life activity predominantly took place, and mark on that map the attractive (quiet, clean) and unattractive (noisy, dusty) locations. The questionnaire contained closed-ended questions about the environmental qualities of their domain area and open-ended questions about the noisiest and quietest areas in the city and about the least pleasant city noises.

The analysis of the students' maps and responses showed that the size of the subjectively perceived domain area varied in the range of 500-800 $\mathrm{m}$ in diameter and little depended on how well the respondents, by their own assessment, were familiar with the area details. The respondents usually defined the subjective domain area as the area bounded by the streets that they characterized as the main sources of noise and dust. If the domain area was expanded beyond such streets then most often the expansion included some kind of green zone - a park or a square, or some perceived attractive leisure or necessity (shopping, parking) facility. 
Practically all domain areas contained a mix of attractive and unattractive places, but their proportion varied. When describing their perception of the noisiness of their domain area as a whole, the respondents easily mentally converted noise variations into a general or averaged characteristic expressed in such terms as very noisy, mostly noisy, mostly quiet, etc.

Among the most unpleasant urban noises, the respondents named noise from vehicles, sounds of working construction and repair equipment, crowd noise, shouts of people and advertising promoters, loud music from car cabins. The noisiest areas were the central areas, where the traffic noise overlapped with the noise of the crowd. The quietest were residential areas. Vehicle noise sometimes was the issue there too, but to a lesser extent than in central areas.

The results of the study are interesting and promising from the prospective of the suggested method of average noise estimates. The study confirms that characterization of city districts by average noise levels can be meaningful and useful to city residents; it corresponds to the way they themselves evaluate noisiness of city neighborhoods. The suggested step size of the coarse computational grid (about $500 \mathrm{~m}$ ) is close to the typical size of the areas that residents perceive as the domain area of their habitat (500-800 m). It opens a possibility for verification of our model estimates, at least in a relative sense, by surveying residents' perception of noisiness of the areas surrounding their place of residence or work.

In the proposed here methodology of approximate noise mapping in the city scale we calculate the average noise levels (in a sense of logarithmic averaging) in the cells on the coarse grid using information on the sources (mainly roads) and available data about built-up areas. Noise propagation with simultaneous averaging described in Section 2.2 accounts for the built-up areas by means of $A_{\text {hous, } 1}$ attenuation as defined in ISO. The other noise propagation features can be partially incorporated as well. These average values can be referred to as the background noise values in the cell. They can be modified then with the help of more precise calculations on a fine grid in very limited area alongside the road segments inside the cells using a full model and the local scene data.

In the context of noise mapping strategies adopted in European countries, our work hardly pretends to be in close connection, although formally we compute static maps as multipliers, which can be supplemented by time dependent traffic noise intensity, corrected by measurements, etc.

Our computations provide estimates of the state of the city noise environment. The background noise data can be useful also for local noise estimates both in static and dynamic mode. It is worth to mention the low computational cost of the proposed method, at least at the stage of background noise calculations.

The next Section 2 outlines the method and gives a simple example of its application. The results are compared with calculations by full model Ecolog-Noise approved for usage by Russian Environmental Authorities.

\section{Methods}

\subsection{Geometry and algorithm in general}

City environment is considered as 2D limited domain. We introduce two uniform grids in it with steps $\mathrm{H}$ and $\mathrm{h}(\mathrm{h}<$ $H$ ), namely a coarse grid $G_{H}$ and a fine grid $G_{h}$. Average noise levels are calculated in the grid cells associated with $\mathrm{G}_{\mathrm{H}}, \mathrm{H}$-cells. The fine grid with corresponding h-cells is an auxiliary one used for discretization of the scene. In particular, one can mark building projections by h-points. Thus we can transit, at least partly, from continuous objects to discrete ones. Geometry sketch is shown in Figure 1.

We connect two $\mathrm{H}$-cells $\mathrm{i}$ and $\mathrm{j}$ by the polygon $\mathrm{C}_{\mathrm{ij}}$ shown in Figure 1 and calculate the number $\mathrm{N}$ of h-grid points inside building projections on horizontal plane (white spots). Building density in the polygon $\mathrm{C}_{\mathrm{ij}}$ is then set to

$$
B_{i j}=N h^{2} / A\left(C_{i j}\right)
$$

where $A\left(C_{i j}\right)$ is the area of $C_{i j}$.

Any source of noise in the cell (e.g. a road segment inside) may be also represented by a set of h-grid points with evenly distributed noise intensity. However, as it will be shown in Section 2.2, source contributions to the average value of noise level inside $\mathrm{H}$-cell can be easily calculated straightforward. Note that projecting sources and buildings on the $G_{h}$ would not be needed if accurate enough data are available and the discretization is not advantageous from the prospective of computational time.

Noise sources are distributed over H-cells either by corresponding sets of h-points or as line or area segments of the roads. The average noise level for a given $\mathrm{H}$-cell is computed as a sum of contributions of the noise sources in all $\mathrm{H}$-cells including the given one. Corresponding formulas are in Section 2.2. To include the attenuation by built-up areas, we use the attenuation term $\mathrm{A}_{\text {hous, } 1}$ defined in ISO 9613-2 . It is proportional to a density of buildings, so for each pair of $\mathrm{H}$-cells $\mathrm{i}$ and $\mathrm{j}$, we use the value of density $\mathrm{B}_{\mathrm{ij}}$ (1). 


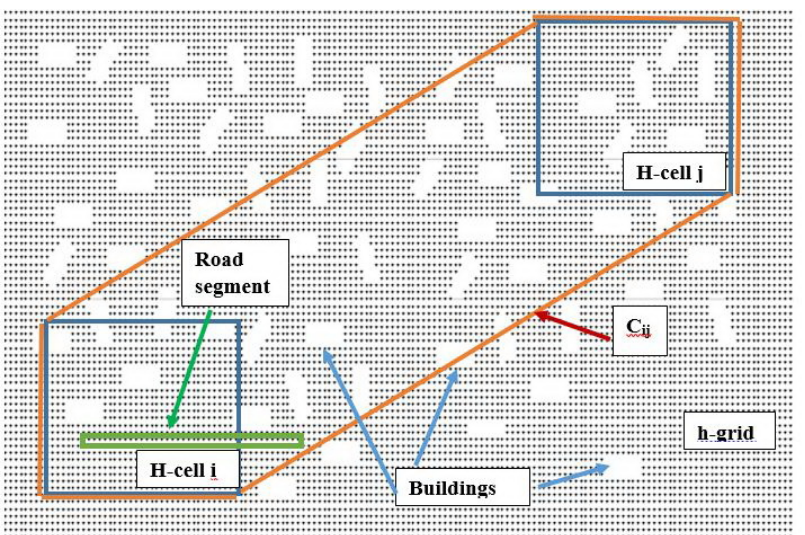

Figure 1: Geometry sketch.

It should be noted that a similar configuration was introduced in our previous work [24], which will be discussed in Section 3.

\subsection{Averaging functions and calculation algorithm}

When describing a contribution of noise generated in one $\mathrm{H}$-cell to noise level in another cell (might be the same as well), we call the first $\mathrm{H}$-cell the source cell and the other one the receptor cell.

We calculate the averages for H-cells by explicit expressions but not as mean values (in logarithmic sense) of pointwise results. To derive corresponding formulas let's substitute the averaging over a square $\mathrm{H}$-cell with averaging over a circle of radius $r=\frac{H}{\sqrt{\pi}}$ with the same area. Without loss of generality, we can consider the center of the cell at $(0,0)$ and the source at $(\mathrm{R}, 0)$. Assuming point source function $p(x)=\frac{1}{2 \pi x^{2}}$ and using polar coordinate system $(\rho$, $\varphi$ ), the average value $P_{a}(R)$ over the circle of radius $r$ reads

$$
\begin{aligned}
& P_{a}(R)=\frac{1}{2 \pi^{2} r^{2}} \int_{0}^{r} \int_{0}^{2 \pi} \frac{\rho}{R^{2}-R \rho \cos (\phi)+\rho^{2}+\alpha} d \phi d \rho= \\
& \frac{1}{2 \pi r^{2}} \ln \left(\frac{\alpha^{2}-R^{2}+r^{2}+\sqrt{\left(\alpha^{2}+R^{2}+r^{2}\right)^{2}-4 R^{2} r^{2}}}{2 \alpha^{2}}\right)
\end{aligned}
$$

where is an auxiliary positive number that makes (2) usable if $R<r$. It can be interpreted as the minimal distance for which the point source function is valid. One can set $\alpha=0$ for $\mathrm{R}>\mathrm{r}$ which gives

$$
\begin{aligned}
& P_{a}(R)=\frac{1}{2 \pi^{2} r^{2}} \int_{0}^{r} \int_{0}^{2 \pi} \frac{\rho}{R^{2}-R \rho \cos (\phi)+\rho^{2}} d \phi d \rho= \\
& -\frac{1}{2 \pi r^{2}} \ln \left(1-\frac{r^{2}}{R^{2}}\right)
\end{aligned}
$$

As a justification for replacing square cells with circles, one can say that we associate results in G-grid points with sound pressure level (SPL) averaged over the area equal to $\mathrm{H}^{2}$. From this prospective, the replacing is consistent. We have overlapping zones and blind spots, but the combined area of the latter is less than $10 \%$, which can be accepted as we do not look for noise hot spots.

By means (2) or (3) one can calculate the contribution to an average value over the circle of radius $r$ of any stretch of the road or a set of sources uniformly distributed in some rectangle. Using coordinate transform, we can always assume that a line segment of the length $\mathrm{D}$ is located in $(-\mathrm{D} / 2$, $\mathrm{D} / 2$ ) along $O X$ axis, a rectangle with the sides $\mathrm{D}_{1}$ and $\mathrm{D}_{2}$ is located in $\left(-\mathrm{D}_{1} / 2, \mathrm{D}_{1} / 2\right) \times\left(-\mathrm{D}_{2} / 2, \mathrm{D}_{2} / 2\right)$ with the center in the origin, and the center of the circle is in some point(x, y). Thus, in case of (3), the contribution of a line segment reads

$$
P_{a} 1(x, y, D)=-\frac{1}{2 \pi r_{0}^{2} D^{\prime}} \int_{-D^{\prime} / 2}^{D^{\prime} / 2} \ln \left(1-\frac{1}{\left(x^{\prime}-\xi\right)^{2}+y^{\prime 2}}\right) d \xi
$$

and the contribution of a rectangle reads

$$
\begin{aligned}
& P_{a} 2\left(x, y, D_{1}, D_{2}\right)=-\frac{1}{2 \pi D_{1}^{\prime} D_{2}^{\prime}} \\
& \int_{-D_{2}^{\prime} / 2}^{D_{2}^{\prime} / 2} \int_{D_{1}^{\prime} / 2}^{D_{1}^{\prime} / 2} \ln \left(1-\frac{1}{\left(x^{\prime}-\xi\right)^{2}+\left(y^{\prime}-\eta\right)^{2}}\right) d \xi d \eta
\end{aligned}
$$

where $x^{\prime}=x / r, y^{\prime}=y / r$ and $D^{\prime}=D / r, D_{1}{ }^{\prime}=D_{1} / r, D_{2}{ }^{\prime}=D_{2} / r$.

It can be shown that for $R \geq 3.3 r$ one can use point source functions instead of averaging functions (2), (3) with the relative error less than $5 \%$. It follows also that in this case the sources inside the same H-cell may be aggregated in a single point source.

The calculation procedure for evaluation of the source contribution in one cell to the average $S P L_{a v}$ over another cell (including the same cell) depends on a distance $\mathrm{R}$ between the cells.

A) Far enough cells $(R \geq 3.3 r)$.

$$
S P L_{a v}=L_{0}-20 \lg (r)-8-\mathrm{A}_{\text {hous }, 1}(R)
$$


B) Close but not adjacent cells $(\mathrm{r}<\mathrm{R}<3.3)$.

Formulas (3) - (5) are utilized depending on sources' type and configuration. Thus, the contribution of the road segment with non-zero width $\mathrm{S}$ and length $\mathrm{D}$ can be obtained by numerical integration

$$
S P L_{a v}=L_{0}-10 \cdot \lg (P(x, y, S, D))
$$

where

$$
\begin{aligned}
& P(x, y, S, D)=-\frac{1}{2 \pi S^{\prime} D^{\prime}} \int_{-D^{\prime} / 2-W^{\prime} / 2}^{D^{\prime} / 2} \int_{W^{\prime} / 2}^{\ln ^{\prime}\left(1-\frac{1}{\rho\left(x^{\prime}, y^{\prime}, \xi, \eta\right)^{2}}\right)} \\
& \frac{10^{0.1 \cdot \mathrm{A}_{\text {ноus }, 1}\left(r \cdot \rho\left(x^{\prime}, y^{\prime}, \xi, \eta\right)\right)}}{\rho} \xi d \eta \\
& \rho\left(x^{\prime}, y^{\prime}, \xi, \eta\right)=\sqrt{\left(x^{\prime}-\xi\right)^{2}+\left(y^{\prime}-\eta\right)^{2}}
\end{aligned}
$$

$\left(\mathrm{x}^{\prime}, \mathrm{y}^{\prime}\right)$ - coordinates of the center of receptor $\mathrm{H}$-cell in transformed coordinate system, $\mathrm{L}_{0}=10 \cdot \lg (\mathrm{W}), \mathrm{W}$ - sound intensity level of the road segment, the apostrophes mean the same as in (4) and (5).

C) Adjacent cells and source cell itself.

Calculations are the same as in B), except (2) is used instead of (3).

A)-C) include function $A_{\text {hous, } 1}$, which in turn includes $B_{i, j}$ values calculated for the pairs of H-cells as described in Section 2.1.

If a road segment is represented by h-points, then the sum over these points corresponds to the integrals in (8). In case of multiple sources within the same cell, each is considered separately, and the usual logarithmic summation follows. Note that the building densities $B_{i j}$ correspond to the pairs of $\mathrm{H}$-cells, so the road going across several $\mathrm{H}$ cells gets split into individual segments per each of these $\mathrm{H}$-cells, and the contributions of each segment to all $\mathrm{H}$-cells are evaluated separately.

As averaging terms in (6)-(8) do not depend on noise frequency band, other factors affecting noise propagation can be taken into consideration. For instance, one can account for the attenuation due to absorption in the atmosphere, attributing it to the distance between the centers of the cells, and subtract it from $\mathrm{L}_{0}$.

Strictly speaking, the term like

$10^{0.1 \cdot A_{\text {Hous }, 1}\left(r \cdot \rho\left(x^{\prime}, y^{\prime}, \xi, \eta\right)\right)}$

in (8) should have been included in (2) or (3) instead of (8). However, in this case the explicit expression in (2) could not have been derived, and computations would take more time. As current algorithm leads to significant underestimation of SPL only in case of source cell itself if it has high building density, we consider the use of (8) suitable. Nevertheless in the future, it would be preferable to use the corrected expressions (2) and (3) for the source cells and speed up the calculations using of appropriate 2D interpolation.

Current method may underestimates results also due to ignoring the obstacle-free space around road stretches and noise reflections from the facades of houses alongside the road. It seems very reasonable to run full model in source cells for grid points in close proximity to the roads using the real configuration of built-up areas in the close proximity to the roads. The final average value for the cell is derived then as weighted mean. Calculation time thus increases but seems not drastically, because the detailed estimates by full model are needed only for very limited parts of source cells, whereas mutual contributions of other cells are still computed on the coarse grid by the proposed here procedure, which is very fast. An example outlined in the next Section 2.3 shows that the combined algorithm improves estimates significantly.

\subsection{Test example}

Simple test example comprises 4 road segments and 112 buildings in the area divided into six $500 \times 500 \mathrm{~m} \mathrm{H}$-cells. A sketch is shown in Figure 2. Buildings were mapped on to the auxiliary 10x10 $\mathrm{m}$ h-grid shown in grey. In accordance with the algorithm outlined in Section 2.2, we determined building densities on the basis of h-grid, as described in Section 2.1. and calculated contributions of sources in A, B, C, E cells to all cells A-F using formulas (7) and (8). Road segments data were set typical for real streets with $\mathrm{L}_{\mathrm{a}, \mathrm{eq}}=72$ $\mathrm{dBa}(\mathrm{A}, \mathrm{C})$ and $76 \mathrm{dBa}(\mathrm{B}, \mathrm{E}) \mathrm{dBa}$ at $7.5 \mathrm{~m}$. We set $\alpha=1$ in (2) corresponding to the minimum distance in the EcologNoise (E-N) software, which we used to compare our results with.

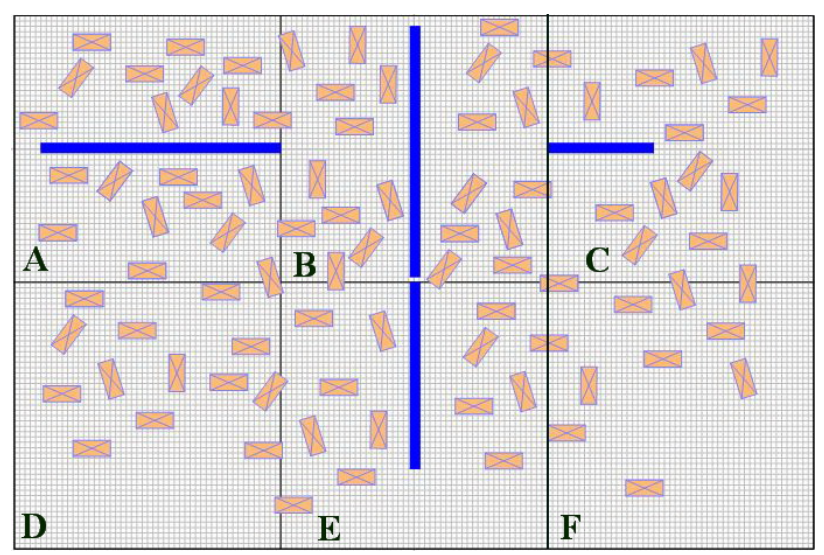

Figure 2: Sketch of test example: blue - road segments, gold buildings, grey $-10 \times 10 \mathrm{~m}$ grid, black $-500 \times 500 \mathrm{~m}$ grid, cells are marked as A-F. 
Contributions of the sources in (A,B,C,E) cells to (A-E) cells were evaluated by our model and E-N. In the latter, the averages were taken from the results over h-grid in every $\mathrm{H}$ cell. In addition to that, we introduced four auxiliary grids around sources the each $\pm 10 \mathrm{~m}$ from them and calculated the mean values over them using E-N. Initial contributions (A to A),..., (E to E) have been corrected (weighted mean) by these additional average noise levels.

Table 1 shows the differences between the results obtained by Ecolog-Noise and by current method. The values in the last column correspond to averages in $\mathrm{H}$-cells (rows of the table). Each cell (x,y), $\mathrm{x}=\{\mathrm{A}, \mathrm{B}, \mathrm{C}, \mathrm{D}, \mathrm{E}, \mathrm{F}\}, \mathrm{y}=\{\mathrm{A}, \mathrm{B}, \mathrm{C}, \mathrm{E}\}$, shows contribution of y $\mathrm{H}$-cell to $\mathrm{x} \mathrm{H}$-cell. For the source cells, average SPLs have been estimated both without correction and with it, hence two differences are shown for such cells in Table 1. First one corresponds to uncorrected estimates and the second one to corrected ones.

Table 1: The differences in $\mathrm{dBa}$ between $\mathrm{E}-\mathrm{N}$ results and current model results.

\begin{tabular}{llllll}
\hline & A & B & C & E & Sum \\
\hline A & $6.3,-1.2$ & 6.7 & 8.4 & -0.4 & $6.3,-1.1$ \\
B & 7.6 & $6.7,0.9$ & 6.4 & 7.8 & $6.8,1.3$ \\
C & 10.3 & 8.4 & $5.9,-2.0$ & -0.4 & $6.0,-1.7$ \\
D & 3.3 & 1.8 & -11.5 & 3.9 & 3.3 \\
E & -0.1 & 5.8 & 2.9 & $5.1,0.6$ & $5.1,0.8$ \\
F & -11.5 & -2.1 & 3.6 & 5.2 & 4.1 \\
\hline
\end{tabular}

There are several conclusions from this simple example. The proposed method predicts background noise responding poorly to high noise values in points along roads. Corresponding correction gives significantly better results. This evident result simply followed from logarithmic averaging. Another point worth mentioning is that the account for building density with $A_{\text {hous, } 1}$ assumes probably that houses are distributed nearly randomly. If they congregate at some particular place across the noise band, they should rather be interpreted as a barrier but not as a built-up area. In our example, it is the case of $\mathrm{A}$ to $\mathrm{F}$ and $\mathrm{C}$ to $\mathrm{D}$ contributions when the B-method (formulas (7) and (8)) overestimates E-N results whilst in general the B-method should rather underestimate full models. However, this particular case might be partly because the E-N program accounts for single reflections only.

The time of computing by Ecolog-Noise was about 30', and by current method - less than $30^{\prime \prime}$ (just 24 numerical integrations), rather fast. The projection of obstacles on to h-grid and calculation of their densities took some time, but it was very fast as well.

\section{Example of the city area}

The next illustrative example is for a dense urban area of about $6 \times 7 \mathrm{~km}$ with approximately 5000 buildings and 170 road segments. Digital map comprised all data in shp format and projection of objects on to the h-grid was done by Ecolog-Noise software. As a result, 42070 grid points corresponding to houses and 1673 to roads were obtained. The fragment of the map is shown in Figure 3.

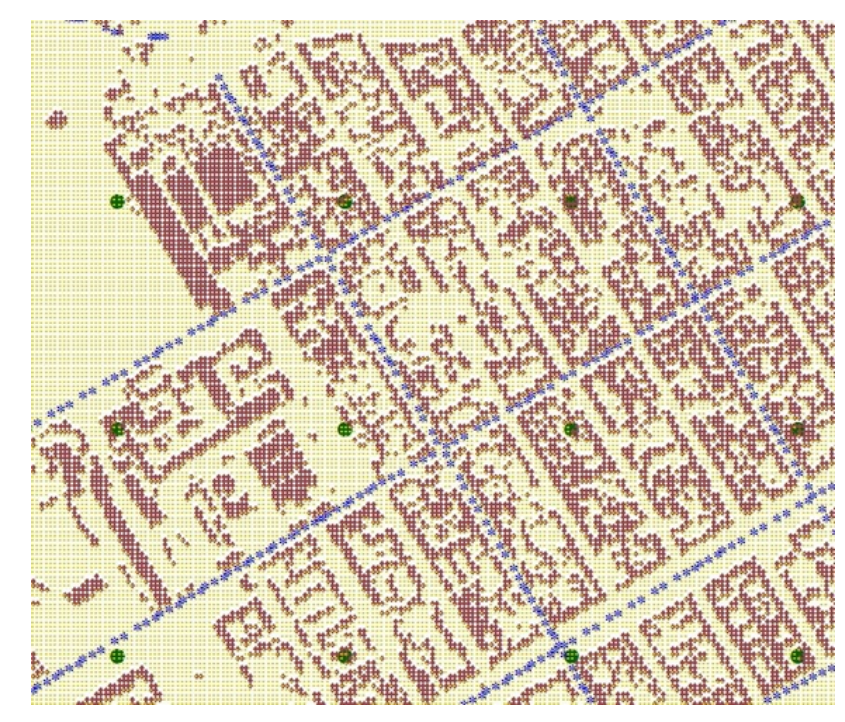

Figure 3: The fragment of urban area with computational grids $\mathrm{G}_{\mathrm{H}}$ and $G_{h}$. Big green dots $G_{H}$ grid points; stars: blue - roads, brown buildings, yellow $G_{h}$ grid points.

Cell-to-cell building densities for $69 \mathrm{H}$-cells were calculated in 13 minute. The densities vary from zero to 0.55 with average value equals to 0.25 . Final calculations of average SPL in H-cells took less than 1 minute. In this case we used (2), (3) as roads were represented by the sets of points. Unfortunately, unlike in the previous example we could not compare these results with calculations by Ecolog-Noise as it was not enough data for obstacles and sources to feed in the E-N program.

Figure 4 shows the SPL dBA map in classed post form together with houses and roads.

We chose also a single cell marked by a large blue circle in Figure 4 to compare the results of three methods: i) the current method, ii) the method described in our previous work [24] and iii) the mixed one. 
In (ii), we considered polygons connecting source and receptor cells (like $C_{i, j}$ in Section 2.1) referred to as "noise bands", but the grid step there was $25 \mathrm{~m}$ instead of 500 $\mathrm{m}$. The nearest to the source $\left(\mathrm{x}_{1}\right)$ shielding of this band by houses and the farthest one $\left(\mathrm{x}_{2}\right)$ were determined. If no shielding found, the direct noise was computed. Otherwise, we computed screened noise using two barriers with the average in the area building height placed at $\mathrm{x}_{1}$ and $\mathrm{x}_{2}$.

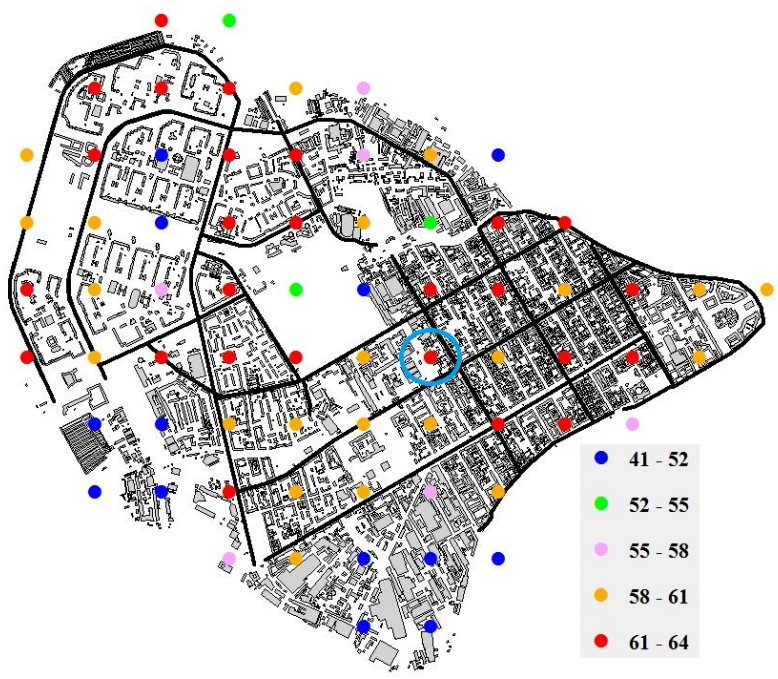

Figure 4: Noise map in selected urban area as a classed post. Grey pixels show houses and black corresponds to roads. It is for the cell in blue circle three methods of estiamting of average SPL were applied.

In current work, this approach was simplified by considering noise bands between h-cells. In the iii) mixed method, we computed point-to-point noise propagation with $A_{\text {hous, } 1}$ attenuation and building density taken from $\mathrm{H}$-cell. In both cases (ii and iii), noise levels were determined in the h-cells external to houses and roads. It would be mentioned that the ii) run took a lot of time in comparison with two others - about 40 minutes vs. about 1 minute. Results for average SPL are as follows i) 61.3, ii) 59.9, iii) 59.1. They are rather close, which partly confirms the suggestion that the current algorithm gives average value without accounting for high noise levels near the roads.

\section{Conclusions}

Noise pollution modelling and corresponding noise mapping is challenging in accurate description of noise propagation in surrounding space. Modelling results are highly sensitive to 3D space geometry. As the difference in com- puted noise levels in neighboring points may be high even on a fine grid, the very idea of noise mapping as an approximation of scalar field by smooth functions becomes not very clear. Partly for this reason, we began to consider the idea of estimating noise levels averaged within rather large areas. The proposed methodology makes possible to add an indicator of noise pollution to a comprehensive assessment of the state of urban environment. According to our research, the suggested resolution for these estimates agrees quite well with the subjective zoning of the noise in the city.

The calculation procedure can be performed as one and two level discretization each describes the processes of different scale - urban background noise and noise due to local sources in quite limited area. It should be noted the flexibility of the method. We construct, in fact, the set of source-cell multipliers. Hence the temporal variation of the sound power of the sources, such as daily variations of traffic, can be easily accounted for.

The background noise estimates can be useful even if they are not very accurate. For instance, having such estimates, one can reduce the number of considered sources (by exclusion of insignificant ones) to save the computational time when computing noise levels locally with full model.

The advantage of the method is that it does not require the detailed information about noise obstacles, and software for its implementation is not very complex. However, the more information is available the more features affecting noise propagation can be included. We realize though that the potential for such improvements is rather limited.

As it is, the proposed methodology makes it possible to add an indicator of noise pollution in urban area to other environmental characteristics, such as air pollution, thus allowing more comprehensive evaluation of the state of urban environment. According to our research, the suggested resolution for these estimates agrees quite well with the subjective zoning of the noise in the city.

Test results seem encouraging, so we hope that the proposed methodology can find the appropriate usage.

Acknowledgement: The authors express their sincere gratitude to the developers of the Ecolog-Noise software, Company "Integral", www.integral.ru, Saint-Petersburg, Russian Federation for their support in this work and provided materials. The authors also express their deep gratitude to Dr Irina Krotova for her valuable comments and help in preparing the manuscript.

Funding information: The authors state no funding involved. 
Author contributions: All authors have accepted responsibility for the entire content of this manuscript and approved its submission.

Conflict of interest: The authors state no conflict of interest.

\section{References}

[1] Bohatkiewicz J. Noise Control Plans in Cities - Selected Issues and Necessary Changes in Approach to Measures and Methods of Protection. In: Transportation Research Procedia. 2016.

[2] Kim M, Chang SI, Seong JC, Holt JB, Park TH, Ko JH, et al. Road traffic noise: annoyance, sleep disturbance, and public health implications. Am J Prev Med [Internet]. 2012 Oct [cited 2014 Nov 27];43(4):353-60. Available from: http://www.sciencedirect.com/science/article/pii/S07493797 12004448

[3] Tobías A, Recio A, Díaz J, Linares C. Health impact assessment of traffic noise in Madrid (Spain). Environ Res. 2015;137:136-40. Available from: http://dx.doi.org/10.1016/j.envres.2014.12.011

[4] Cohen S, Glass DC, Singer JE. Apartment noise, auditory discrimination, and reading ability in children. J Exp Soc Psychol. 1973;9(5):407-22.

[5] Salomons E, Van Maercke D, Defrance J, De Roo F. The Harmonoise sound propagation model. Acta Acust united with Acust. 2011;97(1):62-74.

[6] Kephalopoulos S, Paviotti M, Anfosso-Lédée F. (2012) Common Noise Assessment Methods in Europe (CNOSSOS-EU). EUR 25379 EN. Luxembourg (Luxembourg): Publications Office of the European Union. 2012. JRC72550

[7] Commission Directive 2015/996 establishing common noise assessment methods according to Directive 2002/49/EC of the European Parliament and of the Council, 2016.

[8] Manvell D, Ballarin Marcos L, Stapelfeldt H, Sanz R. SADMAMCombining measurements and calculations to map noise in Madrid. In: INTER-NOISE and NOISE-CON Congress and Conference Proceedings [Internet]. 2004. p. 1998-2005. Available from: http://www.bksv.it/doc/bn0150.pdf

[9] De Coensel B, Sun K, Wei W, Van Renterghem T, SINEAU M, Ribeiro $C$, et al. Dynamic noise mapping based on fixed and mobile sound measurements. In: EURONOISE 2015 [Internet]. MAASTRICHT, France; 2015. p. 6p. Available from: https://hal.archivesouvertes.fr/hal-01470525.

[10] Zambon G, Cambiaghi M, Confalonieri C, Coppolino C, Eduardo $\mathrm{RH}$, Angelini F, et al. Uncertainty of noise mapping prediction related to Dynamap project. INTER-NOISE 2019 MADRID - 48th Int Congr Exhib Noise Control Eng. 2019.

[11] Benocci R, Bellucci P, Peruzzi L, Bisceglie A, Angelini F, Confalonieri $C$, et al. Dynamic noise mapping in the suburban area of Rome (Italy). Environ - MDPI. 2019;6(7):1-17.
[12] Wei W, Van Renterghem T, De Coensel B, Botteldooren D. Dynamic noise mapping: A map-based interpolation between noise measurements with high temporal resolution. Appl Acoust [Internet]. 2016;101:127-40. Available from: https://www.sciencedirect.com/science/article/pii/S0 $003682 X 15002194$.

[13] Tang UW, Wang ZS. Influences of urban forms on traffic-induced noise and air pollution: Results from a modelling system. Environ Model Softw [Internet]. 2007;22(12):1750-64. Available from: https://www.sciencedirect.com/science/article/pii/S1364815 20700028X.

[14] Suárez E, Barros JL. Traffic noise mapping of the city of Santiago de Chile. Sci Total Environ [Internet]. 2014;466-467:539-46. Available from: http://dx.doi.org/10.1016/j.scitotenv.2013.07.013.

[15] Yilmaz G, Hocanli Y. Mapping of noise by using gis in Şanliurfa. Environ Monit Assess. 2006;121(1-3):103-8.

[16] Gulliver J, Morley D, Vienneau D, Fabbri F, Bell M, Goodman $P$, et al. Development of an open-source road traffic noise model for exposure assessment. Environ Model Softw [Internet]. 2015 Jan [cited 2015 Jan 12]; Available from: http://www.sciencedirect.com/science/article/pii/S13648152 1400379X.

[17] Pamanikabud P, Tansatcha M. Geographical information system for traffic noise analysis and forecasting with the appearance of barriers. Environ Model Softw [Internet]. 2003 Dec [cited 2015 Jan 14];18(10):959-73. Available from: http://www.sciencedirect.com/science/article/pii/S13648152 03000975.

[18] Cai M, Yao Y, Wang H. Urban Traffic Noise Maps under 3D Complex Building Environments on a Supercomputer. J Adv Transp. 2018;2018.

[19] Wei W, Botteldooren D, Renterghem T Van, Hornikx M, Forssén J, Salomons E, et al. Urban background noise mapping: The general model. Acta Acust united with Acust. 2014;100(6):1098-111.

[20] Hornikx M, Forssén J, Botteldooren D, van Renterghem T, Wei W, Ögren M, et al. Urban Background Noise Mapping: The Multiple-Reflection Correction Term. Acta Acust united with Acust [Internet]. 2014;100(2):293-305. Available from: http://www.ingentaconnect.com/search/download?pub=info bike://dav/aaua/2014/00000100/00000002/art00014\&mime type=application/pdf.

[21] Ziv A. Discretization and Infographics in Regulatory Calculations of Air Pollution. Proceedings of MGO. 2020; 599: 74-92. Russian.

[22] Chiarini B, D’Agostino A, Marzano E, Regoli A. The perception of air pollution and noise in urban environments: $A$ subjective indicator across European countries. J Environ Manage [Internet]. 2020;263(March):110272. Available from: https://doi.org/10.1016/j.jenvman.2020.110272.

[23] Mitin I. Urban mental maps: history of the term and the diversity of approaches. Urban Stud Pract [Internet]. 2017;2(3):64-79. Available from: https://doi.org/l 0.17323/usp23201764-79.

[24] Ziv A, Solovieva E. Noise as part of the urban environment: the possibility of simplified evaluation of its level. City in the mirror of sciences. Saint-Petersburg; 2015: 68-74. Russian. 